\title{
Estudo comparativo entre o emprego dos extensômetros do tipo Carlson e do tipo de temperatura auto compensável para determinação da retração autógena
}

\section{Comparative study between strain gages for determination of autogenous shrinkage}

\author{
Paulo Francinete Junior ${ }^{1}$, Eugênia Fonseca da Silva ${ }^{2}$, \\ Anne Neiry de Mendonça Lopes ${ }^{3}$
}

\author{
${ }^{1}$ Instituto Federal de Goiás, Rua 75, n 46, Centro, Goiânia, GO, Brasil. \\ e-mail: paulo.junior@ifg.edu.br \\ ${ }^{2}$ Universidade de Brasília - PECC/UnB, Brasília, DF, Brasil \\ e-mail: eugenia@unb.br \\ ${ }^{3}$ Furnas Centrais Elétricas - GST, Aparecida de Goiânia, Goiânia, GO, Brasil \\ e-mail: anne@furnas.com.br
}

\section{RESUMO}

Um dos extensômetros mais indicados para a realização de medidas da retração autógena por meio de extensômetro embutido no concreto são os extensômetros tipo Carlson. No entanto, o seu alto custo normalmente é um fator limitante para seu emprego. Nesse caso, uma alternativa mais econômica seria o emprego dos extensômetros do tipo de temperatura auto compensável. O objetivo principal deste estudo foi verificar se um modelo de extensômetro de temperatura auto compensável pode ser utilizado em substituição ao extensômetro do tipo Carlson para determinação da retração autógena em concretos de alta resistência. Para tanto, procedeu-se a realização de medidas da retração autógena pelo método do extensômetro embutido, para uma mesma mistura de concreto, utilizando os dois tipos de extensômetros. A diferença das médias dos resultados de retração autógena entre esses dois tipos de extensômetros foi tipicamente inferior a $10 \times 10^{-6} \mathrm{~m} / \mathrm{m}$, mostrando que os extensômetros de temperatura auto compensável de embutir no concreto é uma alternativa em substituição ao extensômetro tipo Carlson para a medição da retração autógena do concreto.

Palavra-chave: concreto de alta resistência, retração autógena; Carlson

\section{ABSTRACT}

The Carlson-type strain gages are the most suitable for the measurement of autogenous shrinkage. However, your high cost is usually a limiting factor for your employment. A more economical alternative would be the use of Self-Temperature-Compensation Gages to be embedded in concrete. The main objective of this work was to verify if Self-Temperature-Compensation Gages can be used instead of the Carlson type to determine the autogenous shrinkage in high performance concrete. It was carried out measurements of the autogenous shrinkage, for the same concrete mix, using the two types of extensometers. The difference in the means of the autogenous shrinkage results between these two types of extensometers was typically less than $10 \times 10^{-6} \mathrm{~m} / \mathrm{m}$.

Keywords: high strength concrete; autogenous shrinkage; Carlson

\section{INTRODUÇÃO}

Os avanços na tecnologia do concreto têm permitido a produção de concretos com melhores desempenhos e elevadas resistências. Os concretos de alta resistência (CAR) apresentam uma baixa relação água/cimento e considerável consumo de materiais cimentícios (cimento Portland e adições minerais), resultando numa microestrutura bastante densa e de poros finos [1,2]. Essas características fazem com 
que a retração autógena nos CAR seja significativa, podendo provocar, especificamente nas idades iniciais, fissuração do concreto [1,2]. A ocorrência da retração autógena nos CAR é inevitável, pois esta é causada pelo fenômeno da autodessecação, que é a redução da umidade relativa, durante o endurecimento da pasta de cimento, devido ao consumo de água capilar no processo da hidratação do cimento [3]. Esse fato, associado aos prejuízos que essa retração pode ocasionar aos CAR, mostra a importância de melhor compreendê-la e aprofundar os estudos sobre o tema, com o objetivo de controlá-la a níveis aceitáveis.

Existem diversas metodologias para determinação da variação autógena por meio de medidas de deformação linear. Destacam-se a do Instituto Japonês do Concreto [4] e a do dilatômetro, desenvolvido por Jensen e Hansen [5] e posteriormente normatizado pela Americam Society for Testing Materials [6].

A metodologia proposta pelo Instituto Japonês do Concreto tem sido empregada utilizando, para medição das deformações, relógios comparadores [7-9] ou extensômetros elétricos embutidos nos corpos de prova [2, 10-12]. O uso dos extensômetros embutidos apresenta a vantagem de permitir o início de medida das deformações tão logo se conclua a moldagem e preparação dos corpos de prova.

Um dos extensômetros mais indicados para a realização de medidas da deformação autógena são os extensômetros tipo Carlson que utilizam dois princípios eletromecânicos distintos: o da variação da tensão em fio, que provoca variação da resistência elétrica, e o da variação da alteração da temperatura de um fio, que provoca o mesmo efeito. Desse modo, o extensômetro tipo Carlson funciona também como termômetro, permitindo assim que também sejam determinadas as deformações devido aos efeitos da variação da temperatura [13]. No entanto, o seu alto custo pode ser um fator limitante para seu emprego. Nesse caso, uma alternativa mais econômica seria o emprego dos extensômetros do tipo de temperatura auto compensável.

O princípio básico de operação dos extensômetros do tipo de temperatura auto compensável é similar ao dos extensômetros Carlson [13]. Mas, esses extensômetros não funcionam como termômetros e, portanto, não permitem a determinação da deformação de origem térmica. No entanto, são livres dos efeitos das variações de temperatura. Significa que é um medidor no qual o coeficiente de resistência de temperatura do fio ou lâmina é controlado. Desse modo, se o tipo certo de medidor é usado para o material certo, a expectativa de erro deve estar dentro de $\pm 1,8 \times 10^{-6} /{ }^{\circ} \mathrm{C}$, o que significa uma alta precisão [13].

O extensômetro de temperatura auto compensável pode ser fornecido em seis tipos, dependendo da aplicação: madeira, aço de construção e concreto, aço inox, liga de alumínio, liga de magnésio e plásticos. A Tabela 1 apresenta o coeficiente de dilatação linear para o extensômetro de temperatura controlada em função do tipo de material compatível.

Tabela 1: Característica do extensômetro de temperatura auto compensável em função do tipo de material compatível [13].

\begin{tabular}{l|c}
\hline Objeto de medição compatível & $\begin{array}{c}\text { Coeficiente de dilatação linear } \\
\left(\mathrm{x} 10^{-6} \rho^{\circ} \mathrm{C}\right)\end{array}$ \\
\hline Madeira & 5,0 \\
\hline Aço, concreto & 10,8 \\
\hline Aço inox & 16,2 \\
\hline Liga de alumínio & 23,4 \\
\hline Liga de magnésio & 27,0 \\
\hline Plásticos & 65,0 \\
\hline
\end{tabular}

O objetivo principal deste estudo é verificar se um modelo de extensômetro do tipo de temperatura auto compensável pode ser utilizado em substituição ao extensômetro do tipo Carlson para determinação da retração autógena em concretos de alta resistência.

\section{PROGRAMA EXPERIMENTAL}

\subsection{Materiais}

Aglomerante

O aglomerante hidráulico utilizado na produção do concreto foi o cimento Portland de Alta Resistência Inicial, CP V ARI (NBR 5733) [14]. A Tabela 2 mostra as propriedades físicas e mecânicas 
do cimento empregado, enquanto que a Tabela 3 mostra os componentes químicos.

Tabela 2: Caracterização das propriedades físicas e mecânicas do cimento CP V ARI

\begin{tabular}{|c|c|c|c|c|}
\hline & Propriedades & $\begin{array}{l}\text { Resultado } \\
\text { CP V ARI }\end{array}$ & $\begin{array}{l}\text { Exigências } \\
\text { segundo } \\
\text { NBR } 5733\end{array}$ & Método de ensaio \\
\hline \multirow{2}{*}{ Finura } & Resíduo na \# ABNT 200 (\%) & 0,4 & $\leq 6,0$ & NBR 11579/2012 \\
\hline & Área específica Blaine $\left(\mathrm{cm}^{2} / \mathrm{g}\right)$ & 5440 & $\geq 3000$ & NBR 16372/2015 \\
\hline \multicolumn{2}{|c|}{ Água de consistência da pasta normal (\%) } & 32,4 & n.e & NBR NM 43/2003 \\
\hline \multirow{2}{*}{ Tempo de pega } & Início de Pega (h:min) & $02: 30$ & $\geq 1: 00$ & \multirow{2}{*}{ NBR NM 65/2003 } \\
\hline & Fim de Pega (h:min) & $03: 10$ & $\leq 10: 00$ & \\
\hline \multicolumn{2}{|c|}{ Expansão em autoclave (\%) } & 0,03 & n.e. & ACTM C 151 \\
\hline \multirow{3}{*}{$\begin{array}{c}\text { Resistência à } \\
\text { compressão } \\
(\mathrm{MPa})\end{array}$} & $1 \mathrm{dia}$ & 32,1 & $\geq 14,0$ & \multirow{3}{*}{ NBR 7215/1996 } \\
\hline & 3 dias & 37,2 & $\geq 24,0$ & \\
\hline & 7 dias & 41,8 & $\geq 34,0$ & \\
\hline
\end{tabular}

Tabela 3: Componentes químicos do cimento CP V ARI

\begin{tabular}{|c|c|c|c|c|}
\hline & Componentes Químicos & $\begin{array}{l}\text { Resultado } \\
\text { CP V ARI }\end{array}$ & $\begin{array}{c}\text { Exigência } \\
\text { segundo } \\
\text { NBR } 5733\end{array}$ & Método de ensaio \\
\hline \multicolumn{2}{|c|}{ Perda ao fogo $(\%)$} & 1,82 & $\leq 4,5$ & NBR NM 18/2012 \\
\hline \multicolumn{2}{|c|}{ Resíduo insolúvel (\%) } & 0,79 & $\leq 1,0$ & NBR NM 15/2012 \\
\hline \multicolumn{2}{|c|}{ Trióxido de enxofre $\left(\mathrm{SO}_{3}\right)(\%)$} & 3,28 & $* *$ & \multirow{2}{*}{ NBR NM 16/2012 } \\
\hline \multicolumn{2}{|c|}{ Sulfato de cálcio $\left(\mathrm{CaSO}_{4}\right)(\%)$} & 5,57 & n.e & \\
\hline \multicolumn{2}{|c|}{ Óxido de magnésio $(\mathrm{MgO})(\%)$} & 4,36 & $\leq 6,5$ & \multirow{5}{*}{ NBR NM 11-2/2012 } \\
\hline \multicolumn{2}{|c|}{ Dióxido de silício $\left(\mathrm{SiO}_{2}\right)(\%)$} & 24,41 & n.e & \\
\hline \multicolumn{2}{|c|}{ Óxido de ferro $\left(\mathrm{Fe}_{2} \mathrm{O}_{3}\right)(\%)$} & 3,02 & n.e & \\
\hline \multicolumn{2}{|c|}{ Óxido de alumínio $\left(\mathrm{Al}_{2} \mathrm{O}_{3}\right)(\%)$} & 7,09 & n.e & \\
\hline \multicolumn{2}{|c|}{ Óxido de cálcio $(\mathrm{CaO})(\%)$} & 53,74 & n.e & \\
\hline \multicolumn{2}{|c|}{ Óxido de cálcio livre $(\mathrm{CaO})(\%)$} & 2,16 & $\leq 3,0$ & NBR NM 13/2012 \\
\hline \multirow{3}{*}{$\begin{array}{c}\text { Álcalis totais } \\
(\%)\end{array}$} & Óxido de sódio $\left(\mathrm{Na}_{2} \mathrm{O}\right)$ & 0,29 & n.e & \multirow{6}{*}{ NBR NM 17/2012 } \\
\hline & Óxido de potássio $\left(\mathrm{K}_{2} \mathrm{O}\right)$ & 0,77 & n.e & \\
\hline & Equivalente alcalino em $\left(\mathrm{Na}_{2} \mathrm{O}\right)$ & 0,80 & n.e & \\
\hline \multirow{3}{*}{$\begin{array}{l}\text { Álcalis } \\
\text { solúveis em } \\
\text { água }(\%)\end{array}$} & Oxido de sódio $\left(\mathrm{Na}_{2} \mathrm{O}\right)$ & 0,18 & n.e & \\
\hline & Óxido de potássio $\left(\mathrm{K}_{2} \mathrm{O}\right)$ & 0,64 & n.e & \\
\hline & Equivalente alcalino em $\left(\mathrm{Na}_{2} \mathrm{O}\right)$ & 0,60 & n.e & \\
\hline \multicolumn{2}{|c|}{$\begin{array}{l}\text { ** Quando } \mathrm{C}_{3} \mathrm{~A} \text { do clínquer }<8 \% \text { - limite }<3,0 \\
\quad \text { Quando } \mathrm{C}_{3} \mathrm{~A} \text { do clínquer }>8 \% \text { - limite }<4,5 \\
\text { n.e - não especificado }\end{array}$} & & & \\
\hline
\end{tabular}

Adição mineral

Foram empregadas duas adições minerais na produção do concreto: 1) sílica ativa comercialmente disponível em pó, do tipo não densificada; 2) nanossílica comercialmente disponível em solução aquosa de sílica coloidal com teor de sólidos de $30 \%$.

A Tabela 4 mostra a caracterização física e química da sílica ativa empregada no estudo.

Tabela 4: Caracterização física e química da sílica ativa utilizada

\begin{tabular}{|c|c|c|c|c|}
\hline \multicolumn{2}{|c|}{ Propriedades determinadas } & $\begin{array}{l}\text { Resultado } \\
\text { Sílica ativa }\end{array}$ & $\begin{array}{l}\text { Exigências } \\
\text { NBR } \\
12653 / 12\end{array}$ & Método de ensaio \\
\hline \multicolumn{2}{|c|}{ Massa específica $\left(\mathrm{kg} / \mathrm{m}^{3}\right)$} & 2210 & n.e & NBR NM 23/2001 \\
\hline \multirow{5}{*}{ 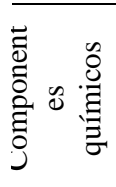 } & Perda ao fogo $(\%)$ & 3,22 & $\leq 10,0$ & NBR NM 15/2012 \\
\hline & Óxido de magnésio (MgO) (\%) & 0,49 & n.e & \multirow{4}{*}{ NBR 13956-2/2012 } \\
\hline & Dióxido de silício $\left(\mathrm{SiO}_{2}\right)(\%)$ & 93,55 & n.e & \\
\hline & Óxido de ferro $\left(\mathrm{Fe}_{2} \mathrm{O}_{3}\right)(\%)$ & 0,16 & n.e & \\
\hline & Óxido de alumínio $\left(\mathrm{Al}_{2} \mathrm{O}_{3}\right)(\%)$ & 0,15 & n.e & \\
\hline
\end{tabular}




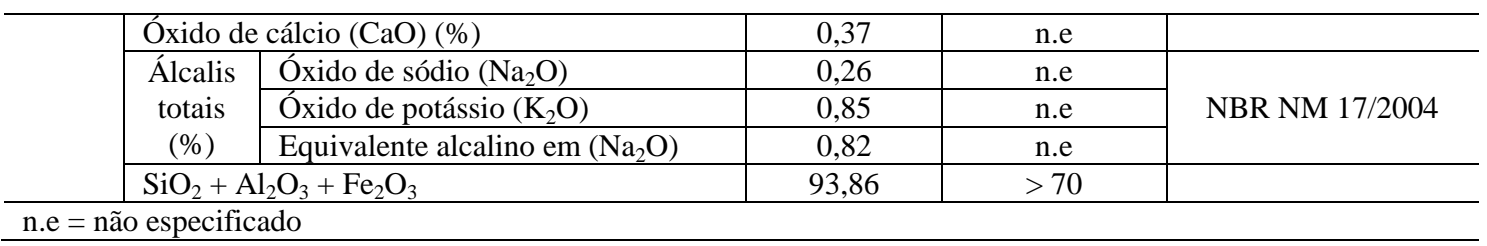

A Tabela 5 apresenta as características da nanossílica empregada no presente estudo. As informações foram fornecidas pelo fabricante.

Tabela 5: Características da nanossílica de acordo com o fabricante

\begin{tabular}{l|c}
\hline Natureza química & Sílica amorfa \\
\hline Apresentação - estado físico & Solução aquosa coloidal - líquido \\
\hline Cor - odor & Claro (ligeiramente turvo) - odor suave \\
\hline Teor de dióxido de silício (\%) & 30 \\
\hline Tamanho aproximado das partículas & $\sim 5 \mathrm{~nm}$ \\
\hline Área superficial & $300 \mathrm{~m}^{2} / \mathrm{g}$ \\
\hline $\mathrm{pH}$ & $10,5(9-11)$ \\
\hline Viscosidade $(\mathrm{MPa} \cdot \mathrm{s})$ & $<50$ \\
\hline Densidade $\left(\mathrm{g} / \mathrm{cm}^{3}\right)$ & 1,2 \\
\hline Teor $\mathrm{NaO}_{2}(\%)$ & 0,55 \\
\hline
\end{tabular}

Para verificar a informação fornecida pelo fabricante, foi determinado o teor de dióxido de silício $\left(\mathrm{SiO}_{2}\right)$ de acordo com os procedimentos indicados nas secções 4.5.4 e 4.5.9 da norma NP EN 196-2:2014, "Métodos de ensaio de cimentos. Parte 2: Análise química dos cimentos" e o resultado foi igual a $29,96 \%$, mostrando estar muito próximo do valor indicado pelo fabricante. Também foi realizada a difração de raios - $\mathrm{x}$ da nanossílica, que confirmou se tratar de um material amorfo, como mostra a Figura 1 .

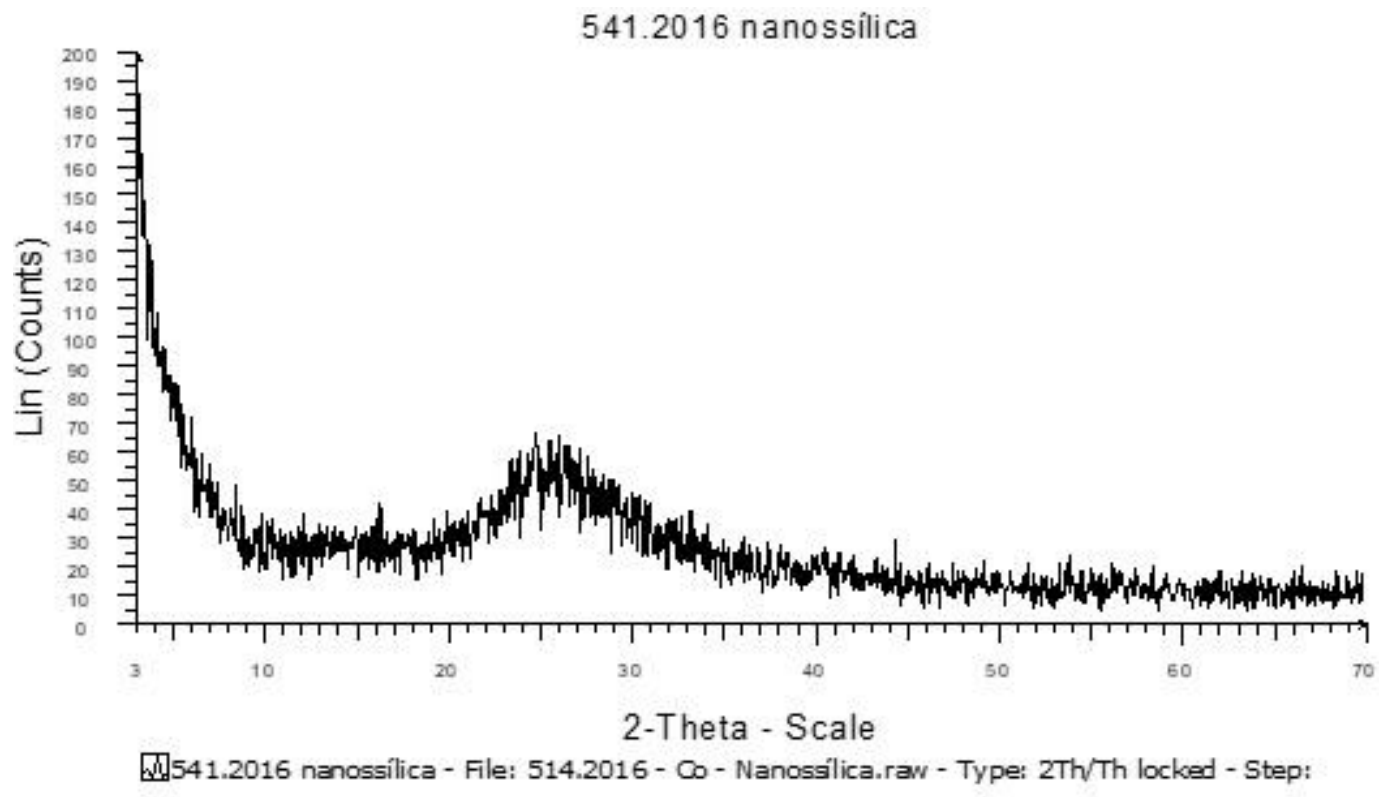

Figura 1: Perfil difratométrico da nanossílica empregada no estudo

Agregados

O agregado miúdo utilizado foi areia natural lavada proveniente do depósito aluvial do Rio Corumbá, situado na região de Pires do Rio (GO). O agregado graúdo utilizado foi brita de graduação 
zero, proveniente do britamento de uma rocha do tipo litológico gnaisse ${ }^{1}$, cuja jazida fica localizada no município de Guapó (GO). A Tabela 6 mostra as características dos agregados miúdo e graúdo empregados no estudo.

Tabela 6: Caracterização dos agregados empregados na produção dos concretos

\begin{tabular}{|c|c|c|c|}
\hline Características & Miúdo & Graúdo & Método de ensaio \\
\hline Dimensão máxima característica $(\mathrm{mm})$ & 4,75 & 12,5 & \multirow{2}{*}{ NBR NM 248} \\
\hline Módulo de finura & 2,67 & 5,95 & \\
\hline Índice de forma pelo paquímetro (c/e) & - & 1,9 & NBR 7809 \\
\hline Coeficiente de inchamento médio & 1,37 & - & \multirow{2}{*}{ NBR 6467} \\
\hline Umidade crítica (\%) & 2,9 & - & \\
\hline Absorção (\%) & 0,3 & 0,3 & \multirow{4}{*}{$\begin{array}{l}\text { NBR NM } 52 / \\
\text { NBR NM } 53\end{array}$} \\
\hline Massa específica na condição seca $\left(\mathrm{kg} / \mathrm{m}^{3}\right)$ & 2630,0 & 2770,0 & \\
\hline Massa específica na condição SSS $\left(\mathrm{kg} / \mathrm{m}^{3}\right)$ & 2640,0 & 2730,0 & \\
\hline Massa específica $\left(\mathrm{kg} / \mathrm{m}^{3}\right)$ & 2650,0 & 2710,0 & \\
\hline Teor de matéria orgânica (+/- clara) & + clara & - & NBR NM 49 \\
\hline Massa unitária no estado solto $-\operatorname{seco}\left(\mathrm{kg} / \mathrm{m}^{3}\right)$ & 1624,6 & 1546,9 & \multirow{5}{*}{ NBR NM 45} \\
\hline Índice de Volume de Vazios - M. Unit. Solto (\%) & - & 44,16 & \\
\hline Massa Unit. Estado Compactado - Seco - $\left(\mathrm{kg} / \mathrm{m}^{3}\right)$ & - & 1618,5 & \\
\hline Massa Unit. Estado Compactado - SSS - $\left(\mathrm{kg} / \mathrm{m}^{3}\right)$ & - & 1629,8 & \\
\hline Índice de Volume de Vazios (\%) & - & 41,57 & \\
\hline Teor de material pulverulento (\%) & 4,14 & 1,52 & NBR NM 46 \\
\hline Teor de argila em torrões e materiais friáveis (\%) & 0,03 & - & NBR 7218 \\
\hline
\end{tabular}

Aditivo

$\mathrm{O}$ aditivo químico utilizado foi do tipo redutor de água de grande eficiência (superplastificante de $3^{\mathrm{a}}$ geração), à base de éter policarboxílico. A Tabela 7 mostra a características do aditivo químico, fornecidas pelo fabricante.

Tabela 7: Caracterização do aditivo superplastificante (fornecida pelo fabricante)

\begin{tabular}{l|c}
\hline Característica & Aditivo Superplastificante \\
\hline Base química & Eterpolicarboxilato \\
\hline Função principal & Superplastificante \\
\hline Aspecto & Líquido viscoso \\
\hline Cor & Branco turvo \\
\hline Viscosidade & $<150 \mathrm{cps}$ \\
\hline Massa específica $\left(\mathrm{g} / \mathrm{cm}^{3}\right)$ & $1,067-1,107$ \\
\hline $\mathrm{pH}$ & $6,0 \pm 1,0$ \\
\hline Teor de cloretos $(\%)$ & Isento \\
\hline
\end{tabular}

\subsection{Produção do concreto}

Foi produzido um concreto com abatimento igual a $200 \pm 10 \mathrm{~mm}$, conforme apresentado na Tabela 8 .

Tabela 8: Traço unitário do concreto

\begin{tabular}{c|c|c|c|c|c|c}
\hline \multicolumn{4}{c|}{ Composição unitária $(\mathrm{kg} / \mathrm{kg}$ de cimento) } & \multicolumn{2}{c}{ Composição unitária (\% da massa de cimento) } \\
\hline Cimento & Sílica & Areia $^{2}$ & Brita & Água & Nanossílica & Aditivo Superplastificante \\
\hline 1 & 0,10 & 1,914 & 1,686 & 0,30 & 1 & 2,69 \\
\hline
\end{tabular}

Para produção dos concretos, inicialmente se fez a imprimação da betoneira com argamassa e então, após a pesagem dos materiais, os mesmos eram colocados na betoneira na seguinte ordem: agregado graúdo, agregado miúdo e cimento. Esses materiais eram misturados a seco durante 4 minutos.

\footnotetext{
${ }^{1}$ Gnaisse é uma rocha de origem metamórfica, composta por diversos minerais, sendo mais de $20 \%$ de feldspato potássico, plagioclásio, e ainda quartzo e biotita.

${ }^{2}$ Areia na condição Saturada Superfície Seca (SSS)
} 
Ao final dessa mistura e sem desligar a betoneira, a água, previamente misturada com o aditivo superplastificante e a nanossílica, era lançada à mistura durante um intervalo de tempo de 1 minuto. Após a adição da água procedeu-se a mistura por 6 minutos, em seguida foi verificada a consistência pelo ensaio do abatimento do concreto no tronco de cone, conforme a norma NBR NM 67 [15]. Após constatar que a mistura atingia o parâmetro de consistência determinado, passou-se para a etapa de moldagem de corpos de prova.

\subsection{Métodos}

No presente estudo foi determinada a retração autógena do concreto por meio do método do extensômetro embutido, fundamentado nas prescrições da Instrução de Trabalho IT.MC 201 [16] do laboratório de concreto de Furnas Centrais Elétricas. Procedeu-se a realização de medidas da retração autógena, em corpos de prova com as mesmas dimensões e moldados com o mesmo concreto. As variáveis foram somente o tipo de extensômetros empregados.

A preparação e produção dos corpos de prova que foi empregada está descrita de forma resumida a seguir:

- Revestiu-se os moldes prismáticos com dimensões $75 \times 75 \times 285 \mathrm{~mm}$ com folhas de poliestireno expandindo de $5 \mathrm{~mm}$ de espessura no fundo e nas faces laterais, a fim de diminuir o atrito e permitir a livre movimentação da amostra do material no interior do molde. A Figura 2 mostra o molde prismático utilizado e o mesmo com o poliestireno;

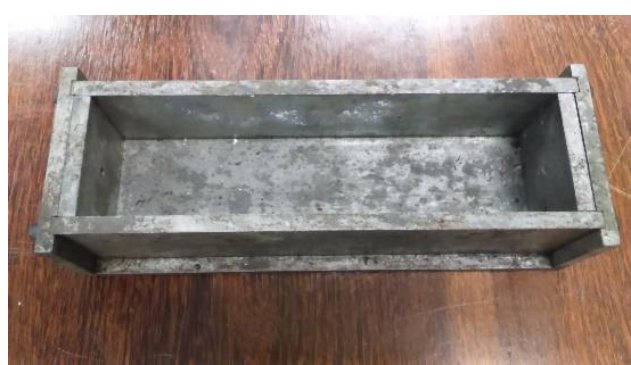

(a)

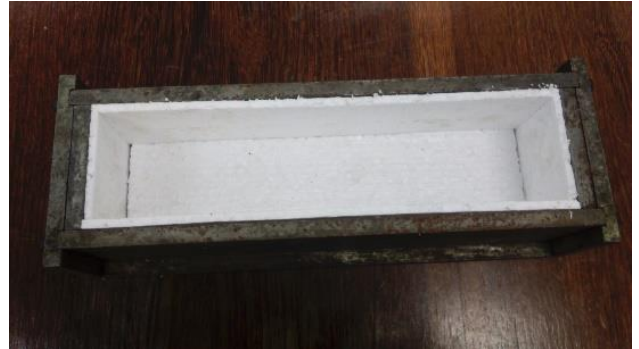

(b)

Figura 2: Forma prismática 75x75x285mm (a) e a mesma forma forrada com poliestireno expandido (b)

- Instalou-se o extensômetro no interior do molde, fazendo-o coincidir com o eixo longitudinal do molde, como mostra a Figura 3;

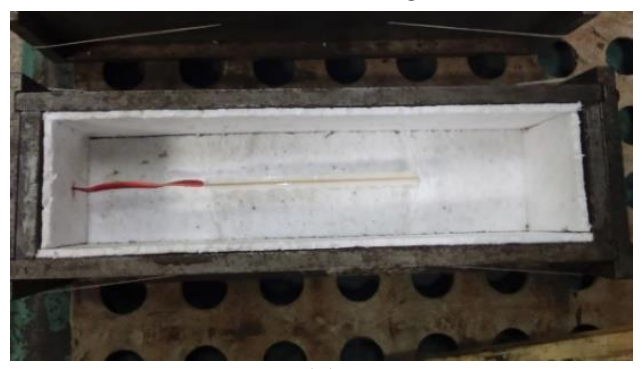

(a)

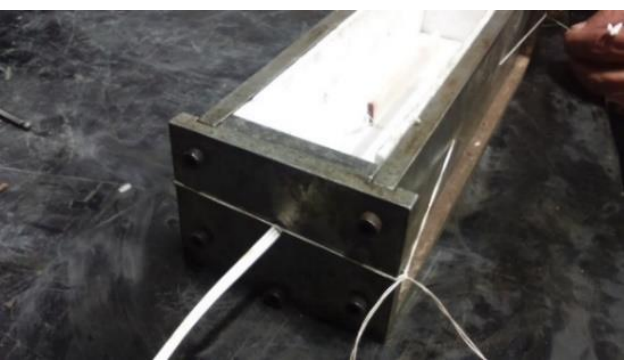

(b)

Figura 3: Extensômetro no interior do molde (a), com detalhe da fixação e saída do cabo de leitura (b)

- Produziu-se o concreto em uma sala com temperatura igual a $21 \pm 2{ }^{\circ} \mathrm{C}$. Os equipamentos e materiais constituintes também se encontravam nessa temperatura. Era anotada a hora em que a água de amassamento era adicionada à mistura;

- Moldou-se os corpos de prova em duas camadas de alturas aproximadamente iguais, adensadas mecanicamente em mesa vibratória. Tomou-se o cuidado para que o extensômetro não fosse avariado ou deslocado da sua posição durante as operações de moldagem e adensamento. A Figura 4 apresenta a moldagem do corpo de prova com extensômetro embutido; 


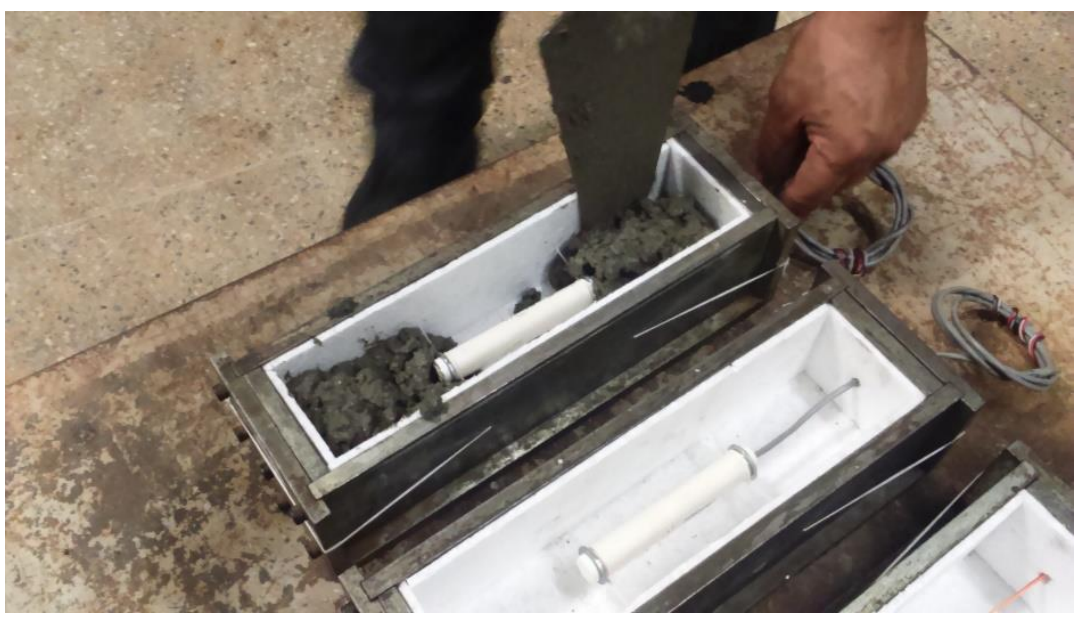

Figura 4: Moldagem do corpo-de-prova com extensômetro embutido

- Selou-se os corpos de prova, imediatamente após a moldagem, a fim de evitar a perda de água para o ambiente. Na selagem dos corpos de prova foram utilizados filme plástico e fita adesiva, se empregando no mínimo 5 camadas de filme e 2 de fita adesiva;

- Mediu-se a massa do conjunto e levou para a sala de ensaios, com umidade $(50 \pm 2 \%)$ e temperatura $\left(21 \pm 2{ }^{\circ} \mathrm{C}\right)$ controladas. A determinação da massa do molde preenchido era para avaliar a perda de massa de água, verificada após o término do ensaio (28 dias);

- Iniciou-se as determinações de variação autógena no instante do patamar de percolação, determinado por meio propagação do pulso ultrassônico [1];

- Realizou-se leituras diariamente até os 28 dias de idade;

- Ao final de 28 dias se verificou a massa do conjunto e retirou o corpo de prova do molde;

A Figura 5 mostra o ensaio de determinação da variação autógena do concreto pelo método do extensômetro embutido.

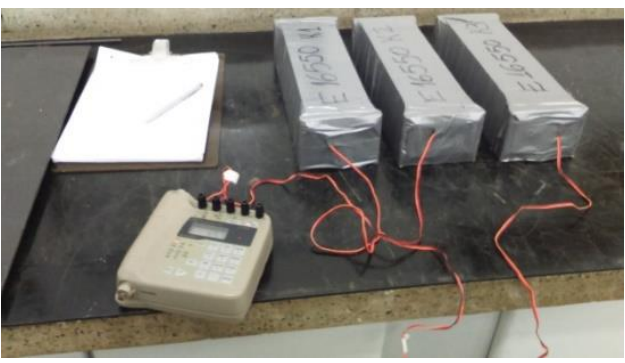

(a)

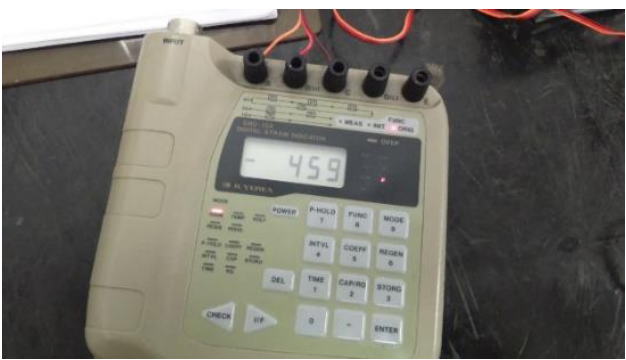

(b)

Figura 5: Ensaio de variação autógena (a) e detalhe da medida de deformação (b)

Foram testados o extensômetro tipo Carlson M-4, cuja as características são apresentadas na Tabela 9, e o extensômetro do tipo de temperatura auto compensável de resistência elétrica igual a $120 \Omega$.

Tabela 9: Características do extensômetro tipo Carlson M-4 [13].

\begin{tabular}{l|c}
\hline Característica & Extensômetro tipo Carlson $\mathrm{M}-4$ \\
\hline Amplitude (milionésimo) & 3900 \\
\hline Menor leitura (milionésimo) & 5,8 \\
\hline Menor leitura de temperatura $\left({ }^{\circ} \mathrm{F}\right)$ & $0,1\left(-1,72{ }^{\circ} \mathrm{C}\right)$ \\
\hline Comprimento de medição (pol.) & $4,062(103,17 \mathrm{~mm})$ \\
\hline Massa (libra) & $0,2(90,72$ gramas $)$ \\
\hline
\end{tabular}

Para facilitar a compreensão e identificação dos dois tipos de extensômetros, o tipo Carlson M-4 
será chamado apenas de Carlson e o tipo de temperatura auto compensável será denominado de AC120. Em função do custo $^{3}$ dos extensômetros, foram moldados seis corpos de prova, sendo dois com extensômetro tipo Carlson (CP1 Carlson e CP2 Carlson) e quatro com extensômetro de temperatura auto compensável (CP1 AC120, CP2 AC120, CP3 AC120 e CP4 AC120). A Figura 6 mostra os dois modelos de extensômetros que foram estudados.

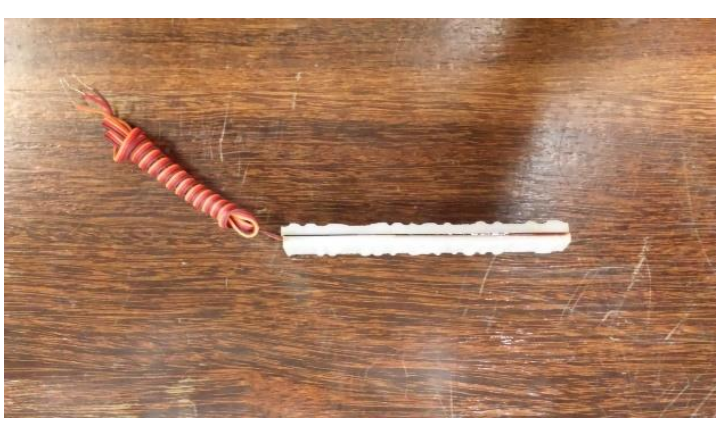

(a)

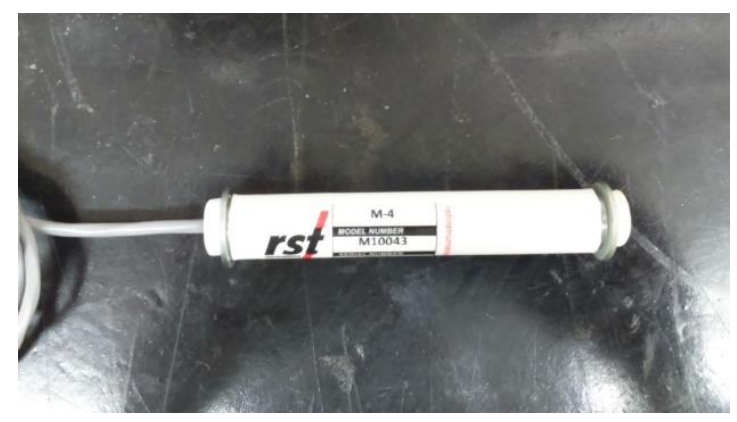

(b)

Figura 6: Extensômetro de temperatura auto compensável (a) e tipo Carlson (b).

\section{RESULTADOS E DISCUSSÃO}

A perda de massa de água foi determinada para cada corpo de prova, com o objetivo de verificar se a retração avaliada foi um fenômeno eminentemente autógeno ou se o corpo de prova sofreu secagem considerável. A perda de massa de água dos corpos de prova, em relação à massa total, ao final do ensaio (28 dias) de variação autógena foi $0,04 \%$, em média. Portanto, pode-se afirmar que houve uma boa selagem dos corpos de prova e que a retração medida se trata realmente de retração autógena.

A Tabela 10 e a Figura 7 apresentam os resultados obtidos para a variação autógena ao longo do tempo, de todos os corpos de prova testados.

Tabela 10: Resultados de retração autógena $(\mu \mathrm{m} / \mathrm{m})$ em função da idade e tipo de extensômetro

\begin{tabular}{c|c|c|c|c|c|c|c|c|c|c|c|c}
\hline $\begin{array}{c}\text { Idade } \\
\text { (dias) }\end{array}$ & $\begin{array}{c}\text { CP1 } \\
\mathrm{AC} 120\end{array}$ & $\begin{array}{c}\mathrm{CP} 2 \\
\mathrm{AC} 120\end{array}$ & $\begin{array}{c}\mathrm{CP} 3 \\
\mathrm{AC} 120\end{array}$ & $\begin{array}{c}\mathrm{CP} 4 \\
\mathrm{AC} 120\end{array}$ & Média & $\begin{array}{c}\text { Desvio } \\
\text { Padrão }\end{array}$ & $\begin{array}{c}\text { CV } \\
(\%)\end{array}$ & $\begin{array}{c}\text { CP1 } \\
\text { Carlson }\end{array}$ & $\begin{array}{c}\text { CP2 } \\
\text { Carlson }\end{array}$ & Média & $\begin{array}{c}\text { Desvio } \\
\text { Padrão }\end{array}$ & $\begin{array}{c}\text { CV } \\
(\%)\end{array}$ \\
\hline 0 & 0 & 0 & 0 & 0 & 0 & 0 & & 0 & 0 & 0 & 0 & \\
\hline 1 & -75 & -83 & -107 & -86 & -88 & 14 & 16 & -151 & -105 & -128 & 32 & 25 \\
\hline 2 & -142 & -150 & -178 & -165 & -159 & 16 & 10 & -160 & -130 & -145 & 21 & 14 \\
\hline 3 & -180 & -192 & -207 & -196 & -194 & 11 & 6 & -185 & -182 & -183 & 2 & 1 \\
\hline 6 & -238 & -246 & -254 & -245 & -246 & 7 & 3 & -235 & -235 & -235 & 0 & 0 \\
\hline 7 & -250 & -260 & -260 & -250 & -255 & 6 & 2 & -250 & -250 & -250 & 0 & 0 \\
\hline 8 & -259 & -265 & - & - & -262 & 4 & 2 & -249 & -254 & -252 & 3 & 1 \\
\hline 9 & -266 & -274 & -277 & -265 & -271 & 6 & 2 & -260 & -264 & -262 & 3 & 1 \\
\hline 10 & -274 & -275 & -280 & -269 & -275 & 5 & 2 & -264 & -269 & -267 & 3 & 1 \\
\hline 11 & -283 & -286 & - & - & -285 & 2 & 1 & -275 & -279 & -277 & 3 & 1 \\
\hline 13 & -294 & -295 & -291 & -282 & -291 & 6 & 2 & -290 & -285 & -288 & 4 & 1 \\
\hline 14 & -300 & -299 & -295 & -287 & -295 & 6 & 2 & -296 & -299 & -297 & 3 & 1 \\
\hline 15 & -305 & -303 & -300 & -292 & -300 & 6 & 2 & -300 & -299 & -300 & 1 & 0 \\
\hline 16 & -306 & -308 & -300 & -298 & -303 & 5 & 2 & -299 & -303 & -301 & 3 & 1 \\
\hline 17 & -321 & -310 & -310 & -301 & -311 & 8 & 3 & -299 & -307 & -303 & 6 & 2 \\
\hline 20 & -323 & -318 & - & - & -321 & 4 & 1 & -313 & -317 & -315 & 2 & 1 \\
\hline 21 & -326 & -323 & -309 & -311 & -317 & 9 & 3 & -317 & -321 & -319 & 3 & 1 \\
\hline 22 & -327 & -323 & -322 & -315 & -322 & 5 & 2 & -322 & -325 & -323 & 2 & 1 \\
\hline 23 & -330 & -327 & -330 & -318 & -326 & 6 & 2 & -321 & -325 & -323 & 2 & 1 \\
\hline 24 & -333 & -329 & -330 & -319 & -328 & 6 & 2 & -321 & -329 & -325 & 6 & 2 \\
\hline
\end{tabular}

\footnotetext{
${ }^{3}$ Em novembro de 2015 o extensômetro tipo Carlson M-4 custava R $\$ 1.300,00$ (US\$ 334,44), enquanto que o extensômetro do tipo de temperatura auto compensável era adquirido por R \$ 100,00 (US\$ 25,73).

${ }^{4} \mathrm{CV}=$ Coeficiente de variação
} 


\begin{tabular}{l|l|l|l|l|l|l|l|l|l|l|l|l}
\hline 27 & -344 & -337 & -346 & -328 & -339 & 8 & 2 & -338 & -345 & -341 & 6 & 2 \\
\hline 28 & -351 & -343 & -342 & -334 & -343 & 7 & 2 & -343 & -346 & -344 & 2 & 1 \\
\hline
\end{tabular}

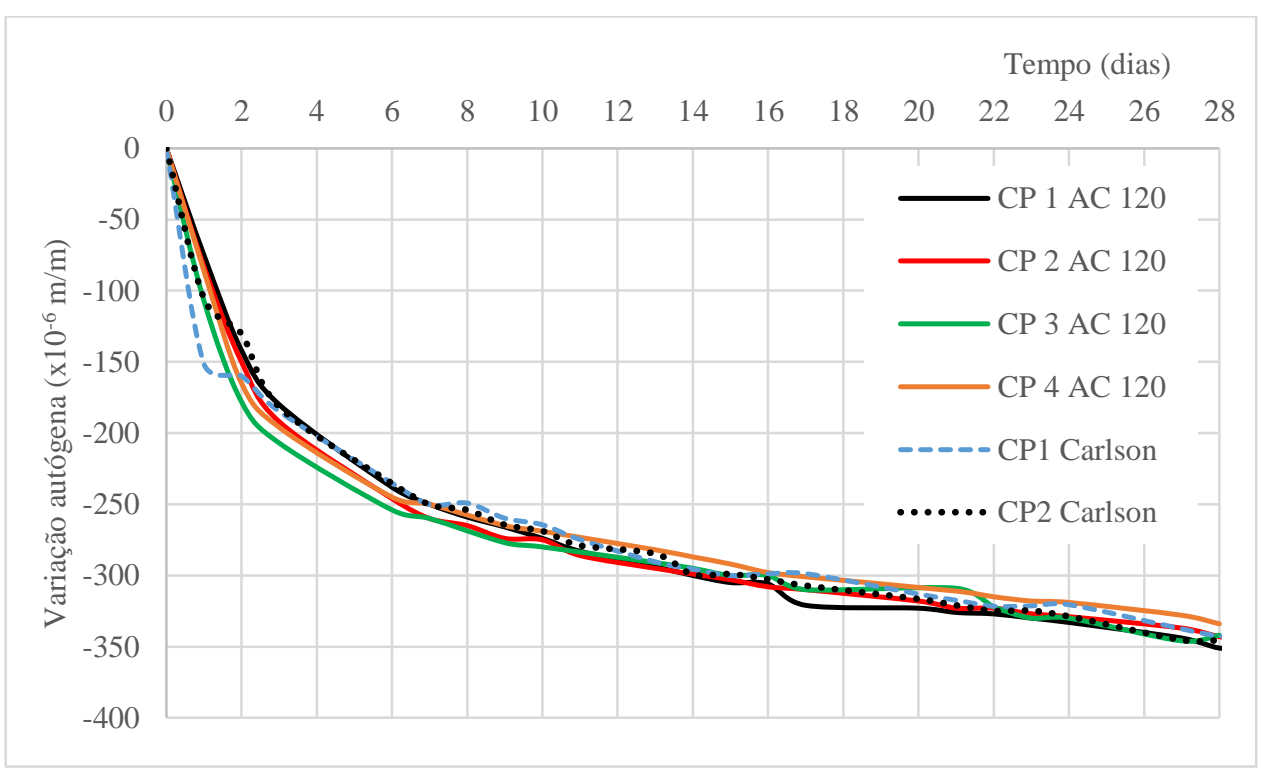

Figura 7: Variação autógena ao longo do tempo de todos os corpos de prova ensaiados

Nota-se na Figura 7 que as curvas de comportamento da variação autógena, ao longo tempo, são bastante similares para todos os corpos de prova, independentemente do tipo de extensômetro utilizado, mostrando uma baixa dispersão dos resultados. Tal observação pode ser melhor visualizada na Tabela 10 que apresenta a média aritmética dos resultados, o desvio padrão e o coeficiente de variação $(\mathrm{CV})$ para cada tipo de extensômetro. Observa-se que dentro de cada tipo de extensômetro as maiores discrepâncias dos resultados ocorreram em 1 dia de idade, sendo que o extensômetro de temperatura auto compensável apresentou coeficiente de variação nessa idade igual a 16\%, enquanto o extensômetro tipo Carlson apresentou, nessa mesma idade, coeficiente de variação igual a $25 \%$. Nas demais idades, o coeficiente de variação foi sempre inferior a $14 \%$, sendo que nas idades superiores a 3 dias esse coeficiente foi sempre igual ou inferior a $3 \%$. Os maiores valores do coeficiente de variação mostrados nos resultados do extensômetro tipo Carlson se deve ao número reduzido de corpos de prova com esse tipo de extensômetro (dois), acredita-se que se caso o número de corpos de prova com esse tipo de extensômetro fosse maior os valores do coeficiente de variação seriam menores. No entanto, mesmo considerando a maior dispersão dos resultados nas idades iniciais, se pode afirmar que ambos os extensômetros apresentam uma boa repetibilidade dos resultados.

Observa-se ainda que a maior diferença entre as médias dos resultados de cada tipo de extensômetro foi de $40 \times 10^{-6} \mathrm{~m} / \mathrm{m}$, também observada em 1 dia de idade. A partir dos 3 dias de idade essa diferença foi tipicamente inferior a $11 \times 10^{-6} \mathrm{~m} / \mathrm{m}$. Para verificar se essas diferenças eram significativas, realizou-se uma análise de variância (ANOVA). O uso da análise de variância na comparação de grupos está baseado na relação da variabilidade dos resultados dentro dos grupos e da variabilidade das médias entre os grupos, e na distribuição de Fischer $(F)$, com o nível de significância $\alpha$ [17-19]. No presente estudo, se adotou no teste estatístico um nível de significância de $5 \%(\alpha=0,05)$, realizado com o programa Statistica $10.0^{\circledR}$. A Tabela 11 mostra os resultados da análise de variância. 
Tabela 11: Análise de Variância verificando a influência do tipo de extensômetro e idade sobre a retração autógena

\begin{tabular}{|c|c|c|c|c|c|c|}
\hline \multicolumn{7}{|c|}{$\mathrm{R}_{\text {mod }}^{2}=0,9887$} \\
\hline Variável & GDL & SQ & MQ & $\mathrm{F}$ & $\mathrm{F}_{0,05}$ & Significância \\
\hline Tipo de extensômetro (A) & 1 & 54 & 54 & 0,8 & 3,964 & Não \\
\hline Idade (B) & 20 & 457164 & 22858 & 340,6 & 1,707 & Sim \\
\hline $\mathrm{AB}$ & 20 & 3148 & 157 & 2,3 & 1,707 & Sim \\
\hline Erro & 78 & 5235 & 67 & & & \\
\hline Total & 119 & & & & & \\
\hline
\end{tabular}

Onde: $\mathrm{R}_{\text {mod }}^{2}=$ coeficiente de determinação do modelo; GDL = grau de liberdade; $\mathrm{SQ}=$ soma dos quadrados; $\mathrm{MQ}=\mathrm{média}$ dos quadrados; $\mathrm{F}=$ parâmetro de Fisher para o teste de significância dos efeitos; $\mathrm{F}_{0,05}=$ parâmetro de Fisher para significância de $5 \%$; Significância $=$ resultado da análise, com a indicação se o efeito é significativo (Sim) ou não é significativo (Não).

Os resultados apresentados na Tabela 11 mostram que mais de $98 \%$ da variação total dos dados é explicada pelo critério adotado, pois $\mathrm{R}_{\text {mod }}^{2}=0,9887$. Observa-se na coluna dos valores de $\mathrm{F}$ que a variável tipo de extensômetro não exerceu efeito significativo nos resultados de retração autógena. Daí, pode-se afirmar que não existem diferenças entre os resultados de retração autógena determinados com o extensômetro do tipo Carlson e com o extensômetro do tipo de temperatura auto compensável, confirmando a eficiência do sistema de temperatura auto compensável e mostrando que esse pode ser empregado em substituição ao tipo Carlson.

A variável idade, como era esperado, apresentou-se como o efeito mais importante $(\mathrm{F}=340,6)$. Como o objetivo do estudo era comparar os dois tipos de extensômetros, não será discutido o comportamento da retração autógena com a idade. No entanto, considerando que a interação entre o tipo de extensômetro e idade também se mostrou significativa, realizou-se uma comparação múltiplas de médias por meio do método de Duncan [17-19], para se determinar se e quais grupos de valores associados à interação entre os tipos de extensômetros e idades diferem entre si. A conclusão foi que, em todas as idades estudadas, os resultados dos dois tipos de extensômetro estão associados entre si em um mesmo grupo, exceto em 1 dia de idade, onde os resultados de cada tipo de extensômetro formam dois grupos que diferem significativamente entre si, como mostra a Figura 8.

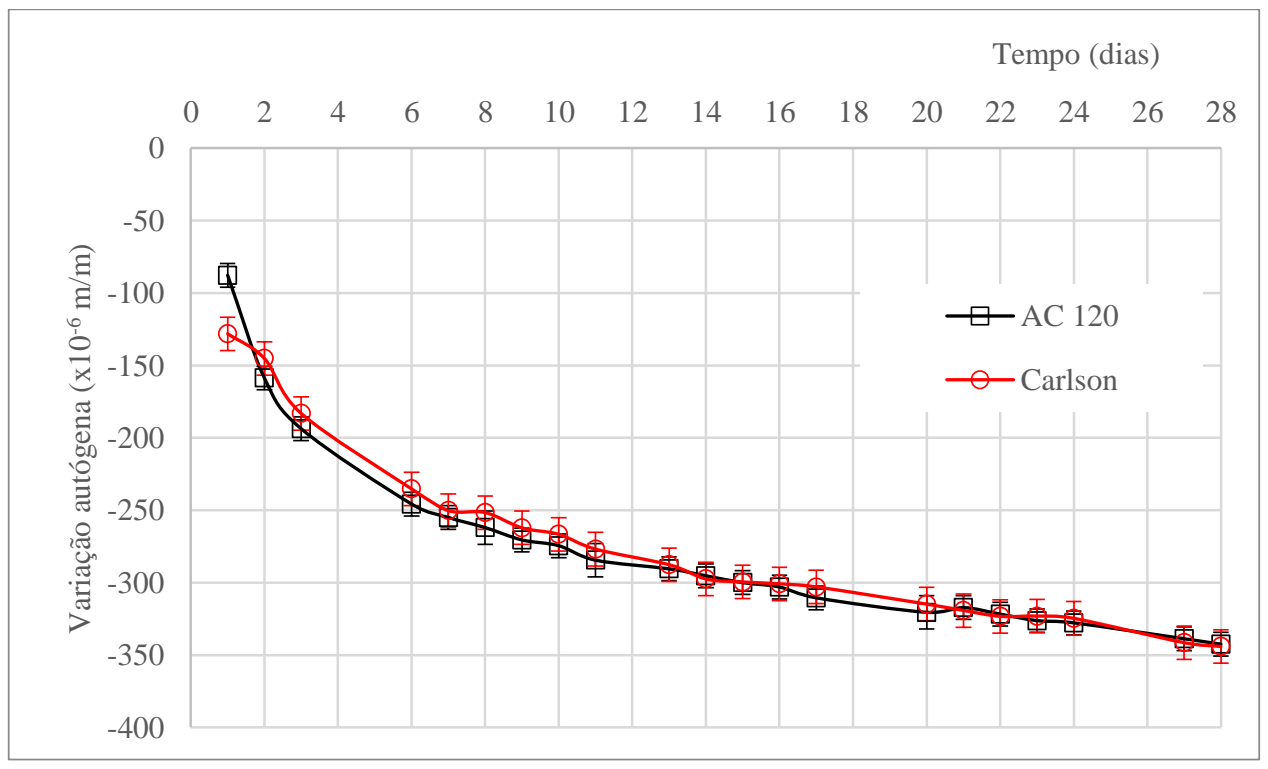

Figura 8:Interação dos resultados médios da retração autógena para cada tipo de extensômetro, com intervalo de confiança de $95 \%$.

Considerando que os extensômetros do tipo Carlson também funcionam como termômetros, o que permite a determinação da deformação devido ao efeito da temperatura, a Figura 9 e a Figura 10 mostram, respectivamente, o gradiente térmico em cada corpo de prova e a deformação de origem térmica. É possível notar um pico no gradiente térmico de $2,5^{\circ} \mathrm{C}$, na idade de 1 dia, resultando numa deformação de origem térmica de $-32 \times 10^{-6} \mathrm{~m} / \mathrm{m}$. Nas demais idades não se observa variação do gradiente térmico superior a $2{ }^{\circ} \mathrm{C}$ e nem deformação de origem térmica maior do que $10 \times 10^{-6} \mathrm{~m} / \mathrm{m}$. Isso pode ser explicado 
pelas dimensões dos corpos de prova empregados no estudo, representando um pequeno volume, não provocando grande quantidade de calor de hidratação e, consequentemente, reduzindo o efeito da variação da temperatura.

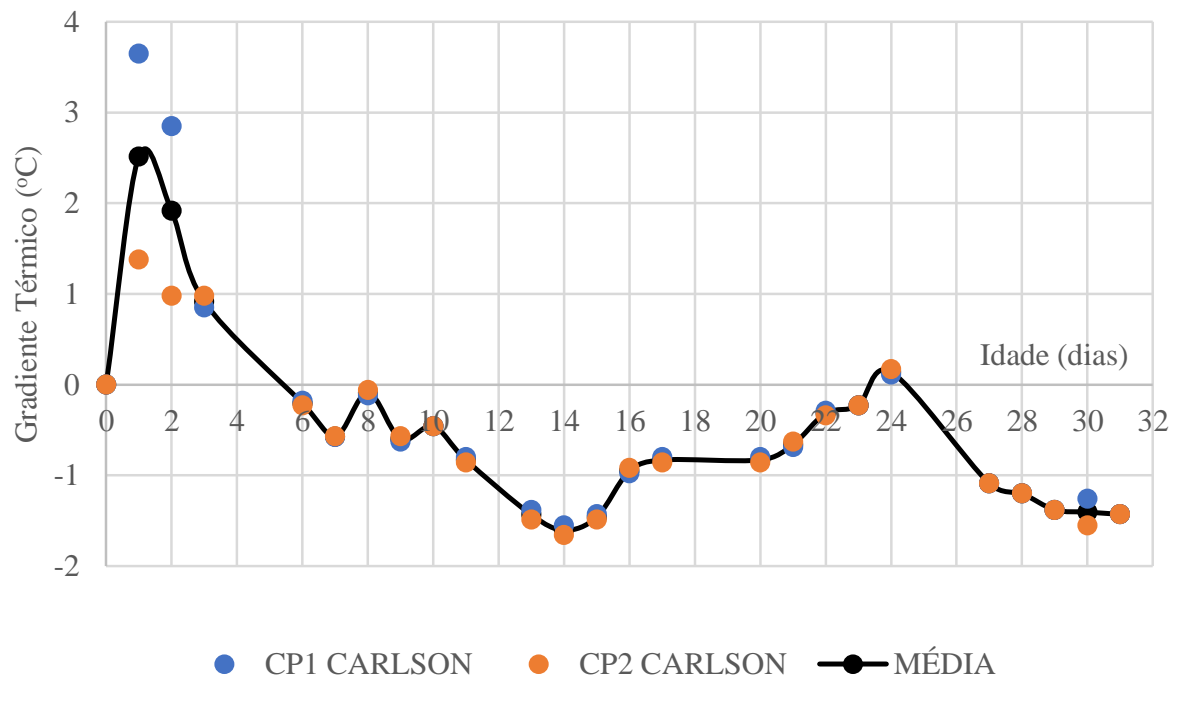

Figura 9: Gradiente térmico registrado nos corpos de prova com extensômetro Carlson.

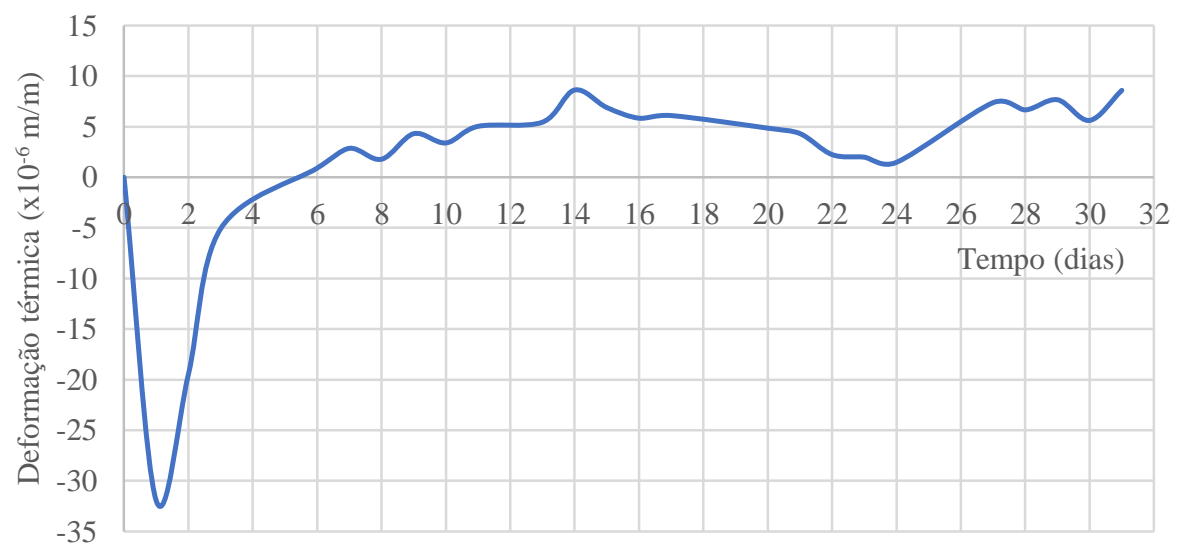

Figura 10: Deformação média devido ao gradiente térmico.

A deformação devido ao gradiente térmico foi descontada da deformação medida nos corpos de prova com o extensômetro do tipo carlson, para verificar a diferença em relação ao resultado obtido quando se leva em consideração a deformação de origem térmica e também com o extensômetro AC 120. A Figura 11 mostra essa comparação. 


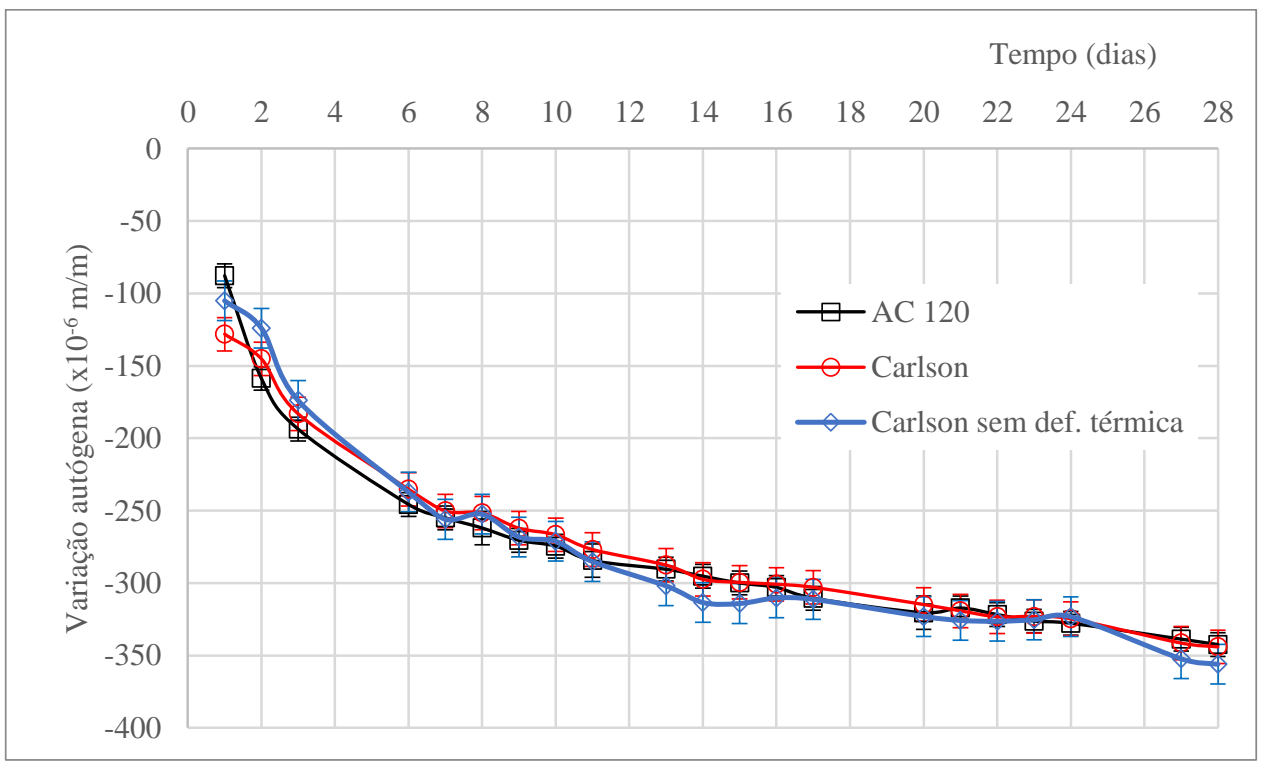

Figura 11: Resultados médios de variação autógena para cada tipo de extensômetro em comparação com o resultado do extensômetro tipo Carlson sem a parcela da deformação de origem térmica.

Nota-se que, as curvas apresentam comportamentos muito similares e que a diferença das médias dos resultados de cada tipo de extensômetro com os resultados do extensômetro tipo Carlson desconsiderando a deformação térmica não são significativas, mostrando que, nas condições do presente estudo, a parcela de deformação de origem térmica é desprezível.

\section{CONCLUSÃO}

Pode-se concluir que os extensômetros de temperatura auto compensável de embutir no concreto é uma alternativa viável em substituição ao extensômetro tipo Carlson para a medição da variação autógena do concreto. A análise estatística mostrou que, em todas as idades estudadas, os resultados dos dois tipos de extensômetros estão associados entre si em um mesmo grupo, exceto em 1 dia de idade, onde os resultados de cada tipo de extensômetro formam grupos que diferem significativamente entre si. A continuidade do estudo com um número maior de corpos de prova e em outras misturas de concreto se faz necessária para validação dos resultados.

A possibilidade do uso do extensômetro de temperatura auto compensável do ponto de vista prático diminui o custo financeiro e/ou possibilita a instrumentação de uma maior quantidade de peças ou elementos estruturais, tanto em laboratórios como em estruturas de concreto, uma vez que o custo do extensômetro de temperatura auto compensável é em torno de 1/10 do custo do extensômetro tipo Carlson.

\section{AGRADECIMENTOS}

Os autores agradecem à Universidade de Brasília, à Furnas Centrais Elétricas, ao Instituto Federal de Goiás e à Coordenação de Aperfeiçoamento de Pessoal de Nível Superior (Capes)

\section{BIBLIOGRAFIA}

[1] SILVA, E. F. Variações dimensionais em concretos de alto desempenho contendo aditivo redutor de retração, Rio de Janeiro, Tese de D.Sc., COPPE/UFRJ, Rio de Janeiro, RJ, Brasil, 2007.

[2] LOPES, A. N. M. Mitigação da retração autógena em concretos de alta resistência contendo aditivo redutor de retração e seus efeitos na macro e microestrutura, Tese de D.Sc., Universidade Federal do Rio Grande do Sul, Escola de Engenharia, Curso de Pós-graduação em Engenharia Civil, Porto Alegre, RS, Brasil, 2011. 
[3] TAZAWA, E., "Technical Committee on Autogenous Shrinkage of Concrete - Committee Report" In: Autogenous Shrinkage of Concrete - Proceedings of the International Workshop organized by Japan Concrete Institute, edited by Ei-Chi Tazawa, E \& FN Spon, London, 1999.

[4] TAZAWA, E., MIYAZAWA, S., "Effect of constituents and curing condition on autogenous shrinkage of concrete", In: Autogenous Shrinkage of Concrete - Proceedings of the International Workshop organized by Japan Concrete Institute, edited by Ei-Chi Tazawa, E \& FN Spon, London, pp. 269-280, 1999.

[5] JENSEN, O.M. e HANSEN, P.F. "A dilatometer for measuring autogenous deformation in hardening Portland cement paste", Materials and Structures, v. 28, n. 7, pp. 406-409, august 1995.

[6] AMERICAN SOCIETY FOR TESTING AND MATERIALS. ASTM C1698: Standard Test Method for Autogenous Strain of Cement Paste and Mortar, Philadelphia, USA, 8p., 2014.

[7] SILVA, E. F., R. MANZANO, M. A. R., LOPES, A.N. M., et al., "Effect of SAP on the Autogenous Shrinkage and Compressive Strength of High-Strength Fine-Grained Concrete", In: International RILEM Conference on Application of Superabsorbent Polymers and Other New Admixtures in Concrete Construction, pp. 211-219, Dresden, 2014.

[8] MANZANO, M. A. R., Estudo Experimental de Materiais Cimentícios de Alta Resistência modificados com Polímeros Superabsorventes (PSAs) como Agentes de Cura Interna, Tese de D.Sc., Universidade de Brasília. Faculdade de Tecnologia, Departamento de Engenharia Civil e Ambiental, Brasília, DF, Brasil, 2016.

[9] SANTOS, T. A. C., Estudo da adição de polímero superabsorvente e de nano partículas de sílica para melhorar propriedades de concretos de alta resistência. Dissertação (Mestrado), Universidade de Brasília. Faculdade de Tecnologia, Departamento de Engenharia Civil e Ambiental, Brasília, Brasil, 2016. [10] AÏTCIN, P.C., "Autogenous shrinkage measurement”, In: Proceedings of the International Workshop on Autogenous Shrinkage of Concrete, pp. 245-256, Hiroshima, Japan, June 1998.

[11] HANEHARA, S., HIRAO, H., UCHIKAWA, H., "Relationships between autogenous shrinkage, the microstructure and humidity changes at inner part of hardened cement paste at early ages", In: Proceedings of the International Workshop on Autogenous Shrinkage of Concrete, pp. 89-100, Hiroshima, Japan, June 1998.

[12] KOJIMA, T., TAKAGI, N., HORIKAWA, S., "Study on Shrinkage Characteristics of High-Strength Silica Fume Concrete", In: Proceedings of Seventh CANMET/ACI International Conference on Fly Ash, Silica Fume, Slag and Natural Pozzolans in Concrete, pp. 719-735, Chennai, India, 2001.

[13] ANDRADE, W. P., Concretos: massa, estrutural, projetado e compactado com rolo: ensaios e propriedades, 1 ed., São Paulo, Editora Pini, 1997.

[14] ABNT, NBR 5733: Cimento Portland de alta resistência inicial, Rio de Janeiro, 1991.

[15] ABNT, NBR NM 67: Concreto - Determinação da consistência pelo abatimento do tronco de cone, Rio de Janeiro, 1998.

[16] FURNAS, IT.MC.201 Concreto - Determinação da variação autógena. Instrução de Trabalho Métodos Construtivos. Furnas Centrais Elétricas S.A. Gerência de Pesquisa, Serviços e Inovação Tecnológica, Aparecida de Goiânia, 2015.

[17] GOMES, F. P. Curso de estatística experimental. USP, ed. 10, Piracicaba-SP, 1982.

[18] NANNI, L. F., RIBEIRO, J. L. Planejamento e avaliação de experimentos, CPGE/UFRGS, Caderno Técnico 17, Porto Alegre-RS, pp. 193, 1987.

[19] MONTGOMERY, D. C., RUNGER, G. C. Applied statistics and probability for engineers, 3rd ed. John Wiley \& Sons, Inc, United States of America, 2003. 